\title{
Article \\ Panx1b Modulates the Luminance Response and Direction of Locomotion in the Zebrafish
}

\author{
Nickie Safarian ${ }^{1,2}$, Sarah Houshangi-Tabrizi ${ }^{1}$, Christiane Zoidl ${ }^{1,2}$ and Georg R. Zoidl ${ }^{1,2, * \text { (D) }}$ \\ 1 Department of Biology, York University, Toronto, ON M3J 1P3, Canada; nsafaria@yorku.ca (N.S.); \\ sarahctc@my.yorku.ca (S.H.-T.); czoidl@yorku.ca (C.Z.) \\ 2 Center of Vision Research, York University, Toronto, ON M3J 1P3, Canada \\ * Correspondence: gzoidl@yorku.ca
}

Citation: Safarian, N.

Houshangi-Tabrizi, S.; Zoidl, C.; Zoidl, G.R. Panx1b Modulates the Luminance Response and Direction of Locomotion in the Zebrafish. Int. J. Mol. Sci. 2021, 22, 11750. https:// doi.org/10.3390/ijms222111750

Academic Editor: Mathieu Vinken

Received: 29 August 2021

Accepted: 23 October 2021

Published: 29 October 2021

Publisher's Note: MDPI stays neutral with regard to jurisdictional claims in published maps and institutional affiliations.

Copyright: (c) 2021 by the authors. Licensee MDPI, Basel, Switzerland. This article is an open access article distributed under the terms and conditions of the Creative Commons Attribution (CC BY) license (https:// creativecommons.org/licenses/by/ $4.0 /)$.

\begin{abstract}
Pannexin1 (Panx1) can form ATP-permeable channels that play roles in the physiology of the visual system. In the zebrafish two ohnologs of Panx1, Panx1a and Panx1b, have unique and shared channel properties and tissue expression patterns. Panx1a channels are located in horizontal cells of the outer retina and modulate light decrement detection through an ATP/pH-dependent mechanisms and adenosine/dopamine signaling. Here, we decipher how the strategic localization of Panx $1 b$ channels in the inner retina and ganglion cell layer modulates visually evoked motor behavior. We describe a panx $1 b$ knockout model generated by TALEN technology. The RNA-seq analysis of 6 days post-fertilization larvae is confirmed by real-time PCR and paired with testing of locomotion behaviors by visual motor and optomotor response tests. We show that the loss of Panx $1 b$ channels disrupts the retinal response to an abrupt loss of illumination and it decreases the larval ability to follow leftward direction of locomotion in low light conditions. We concluded that the loss of Panx1b channels compromises the final output of luminance as well as motion detection. The Panx $1 b$ protein also emerges as a modulator of the circadian clock system. The disruption of the circadian clock system in mutants suggests that Panx1b could participate in non-image forming processes in the inner retina.
\end{abstract}

Keywords: pannexin1b; zebrafish; retinal ganglion cells; Muller glia; circadian clock; visual system; transcriptomics; behavior

\section{Introduction}

Pannexin 1 (Panx1) proteins can assemble into two types of integral membrane channels. It is widely accepted that Panx1 provide a transmembrane pathway for ATP [1]. However, under certain conditions, Panx1 can also act as a highly selective membrane channel for chloride ions without ATP permeability [2]. The cryoEM structure of Panx1 as a heptameric selective chloride channels was resolved recently [2-8]. The expression of Panx1 in the rodent eye has fostered research on functional implications in the normal retina physiology and pathologies related to ocular hypertension or ischemia in mouse models [9-13]. In parallel to ongoing work in rodents, the accessibility of the zebrafish eye at all stages of development to adulthood in combination with the possibility of behavioral assessment of visual system functions allows to study the mechanisms which involve Panx1 in vision using this complementary animal model.

The zebrafish has two gene copies of Panx1, panx1a and panx1b. The ohnologs resulted from the teleost third whole-genome duplication (R3 WGD) event occurring between 320 and 350 million years ago (MYA) [14,15]. The neofunctionalization of both genes is indicated by distinct tissue expression patterns or shared and distinct biophysical properties [15-17]. The panx1b gene shows higher expression levels in the brain and eyes, compared to panx1a $[15,16]$. In a previous study we have shown that in the zebrafish retina, Panx1b's immunoreactivity is prominent in the inner retina and ganglion cells (RGCs) [16], whereas Panx1a is localized on the surface of horizontal cell dendrites invaginating cone 
pedicles [17]. Other prominent biophysical differences are the smaller unitary conductance of Panx $1 \mathrm{~b}$ channels and longer activation time when compared to Panx1a [16].

To the best of present knowledge, the differences between the ohnologs suggest a functional specialization in neuronal circuits shaping visual output of the retina. First evidence was found in the outer retina, where Panx 1 channels affect a slow ATP/pH-mediated mechanism and together with Cx55.5 form a fast ephaptic mechanism tuning feedback from horizontal cells to cones [18]. Next, we showed that Panx1a modulates the detection of light decrements through the retinal OFF-pathway using adenosine and dopaminergic signalling pathways [19]. Here, the roles of Panx1b channels in the inner retina were addressed using a panx $1 b$ knockout model generated with engineered transcription activator-like effector nucleases (TALEN) [20]. RNA-seq data of 6 days post-fertilization (dpf) larvae were confirmed by real-time quantitative PCR (RT-qPCR) and paired with testing of visual-motor behaviors. The results showed that the loss of the Panx $1 \mathrm{~b}$ protein disrupts the retinal response to the abrupt loss of illumination and causes a decreased visual acuity for detecting leftward motion in the dark. This outcome suggests a role of Panx1b in retinal OFF-pathways and directional coding retinal ganglion cell populations. The Gene Ontology (GO) enrichment analysis showed that different to Panx1a, Panx1b does not affect the adenosine-dopamine signaling pathway. Instead, Panx1b emerges as a modulator of the circadian clock system. As roles of Panx1 in the sleep/wake cycle of rodents have been described we propose similar functions of Panx1b in non-image forming processes of the zebrafish visual system.

\section{Results}

\subsection{Targeted Disruption of the panx1b Gene}

For TALEN-mediated genome editing, a single HindIII restriction site in the 4th coding exon of panx $1 b$ was targeted (Figure 1a). Twenty-five picograms (pg) of a pair of TALEN cRNAs was microinjected into one-cell stage embryos. A restriction fragment length polymorphism (RFLP) test of 17 randomly selected larvae at six-day post fertilization (6dpf) revealed a gene editing efficiency of $\approx 88 \%$, as evidenced by a partial loss of the Hind III restriction enzyme recognition sequence located in the spacer region between the TALEN binding sites (Figure 1b). The DNA sequence analysis of multiple F0 larvae confirmed the efficient generation of deletions of varying lengths (Figure 1c). A positive adult F0 founder transmitting an 11-base pair (bp) frameshifting deletion (panx $\left.1 b^{\Delta 11}\right)$ was selected to establish the knockout line $\left(\right.$ pan $\left.x 1 b^{-l-}\right)$ used for further experimentation. The eleven bp deletion caused a frameshift at amino acid E179 of the Panx1b protein, resulting in a premature stop codon. The truncated 179-amino-acid protein Panx $1 b^{\Delta 11}$ lacks the transmembrane regions 3 and 4 , and the entire carboxyterminal domain. The lack of these domains suggested that the mutant was not capable of forming functional Panx1 channels (Figure 1d).

After transient transfection into mouse neuroblastoma 2a (Neuro2a) cell line, the Panx $1 b^{\Delta 11}$-DsRed-monomer protein was detected in the cytoplasm. No significant signal in the cell membrane was visible, implying that the mutant protein was most likely unable to traffic efficiently to the cell membrane (Figure 1e, right panel). The Panx $1 b^{w w}$-EGFP protein was detectable in the perinuclear region and the plasma membrane (Figure 1e, left panel), in line with previous reports $[16,17,21]$.

The Panx1b immunoreactivity in the adult zebrafish retina was found mainly in the inner plexiform layer, and in some ganglion cells (Figure $1 \mathrm{f}-\mathrm{h}$ ), corroborating the previously demonstrated localization identified with a different antibody [16]. The detection of a robust immunoreactivity in GFAP positive structures resembling the end feet of Muller glia was novel. The difference was attributed to replacing the previously reported chicken anti-Panx $1 b$ antibody with an antibody raised in rabbits. The Panx1b immunoreactivity was reduced in panx $1 b^{-/-}$, and absent when the primary antibody was omitted during the staining procedure (Figure $1 \mathrm{~h}, \mathrm{j})$. 
a)

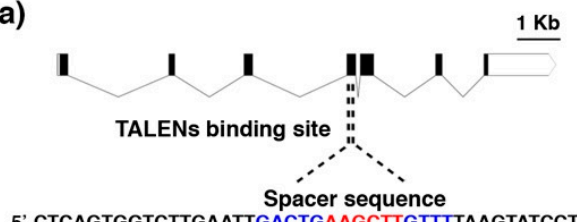
5'-CTCAGTGGTCTTGAATTGACTGAAGCTTGTTTTAAGTATCCTCTGGTAG-3' $\begin{array}{lll}\text { Left arm HindIII Right arm } & \\ & \end{array}$

c)

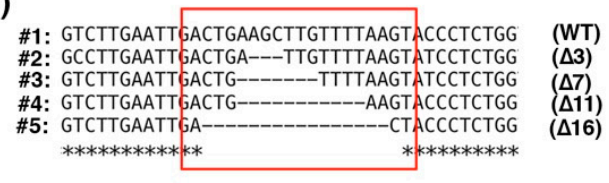

e)

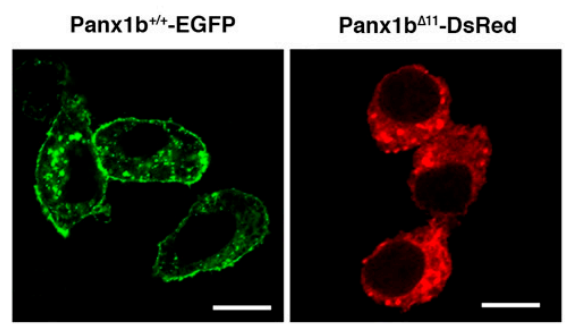

b)

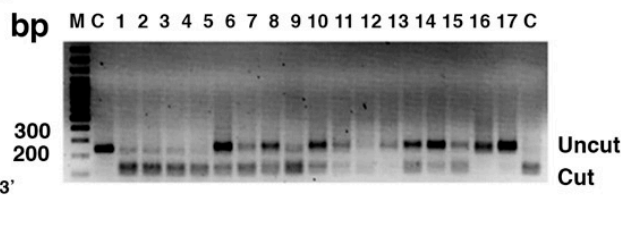

Panx1b ${ }^{\Delta 11}$-DsRed

d)

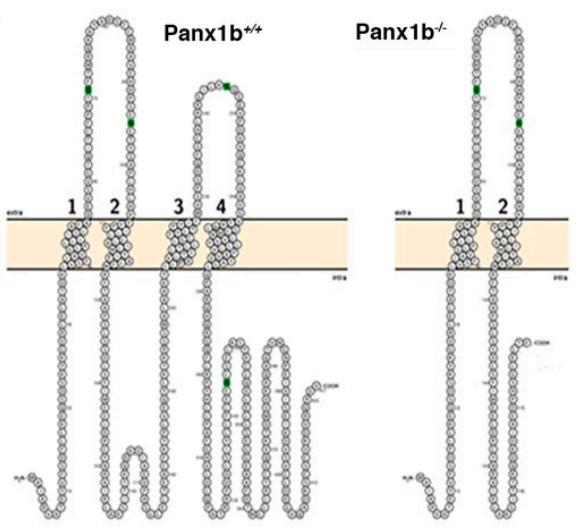

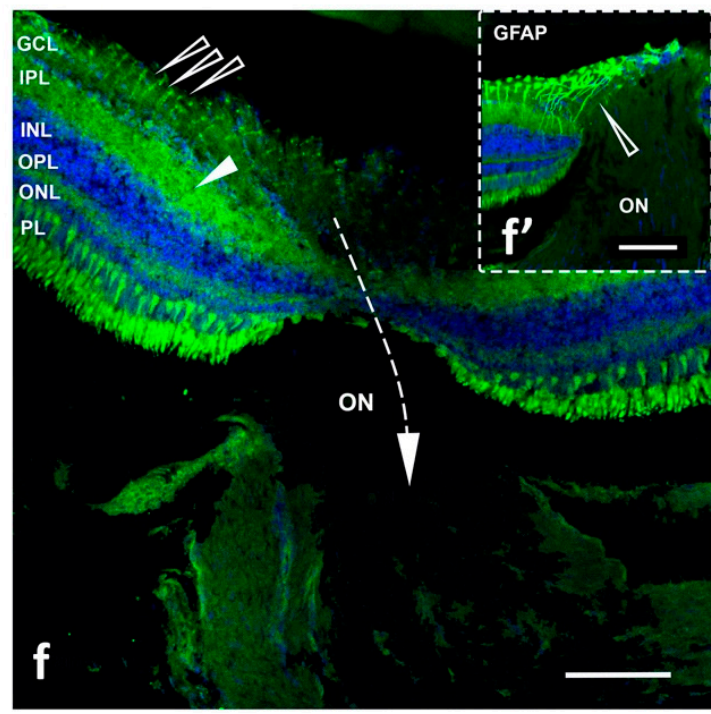
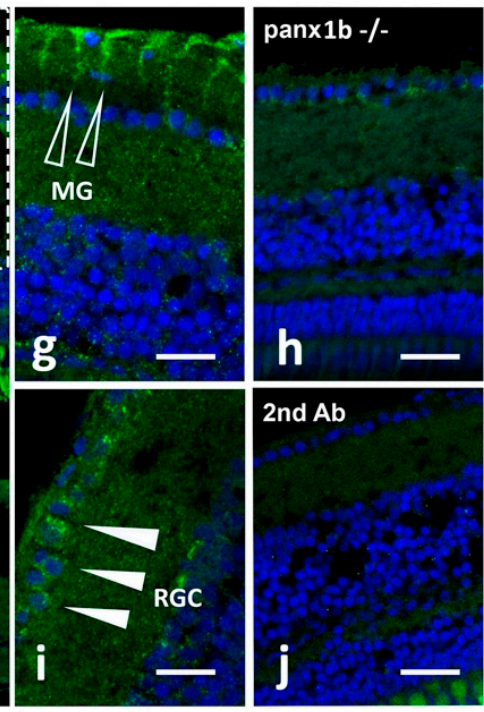

Figure 1. Generating panx $1 b^{-/-}$fish using TALENs. (a) Cartoon depicting the zebrafish panx1b gene structure with seven coding exons. The left and right TALENs binding sequence with the spacer sequence and HindIII restriction site in blue and red is highlighted. (b) The RFLP-assay shows the loss of the HindIII recognition sequence (uncut) in fourteen out of seventeen F0 larvae tested. (c) The sequence alignment demonstrates small ( 3 to $16 \mathrm{bp}$ ) deletions causing frameshift mutations (in red box) in four different F0 larvae. (d) The Protter open-source tool (wlab.ethz.ch/protter, 20 July 2020) visualized the predicted topology of the wild type and mutant Panx1b proteins. The $11 \mathrm{bp}$ deletion in panx $1 b$ exon 4 resulted in a frameshift causing a premature stop codon at amino acid E179. (e) Localization of the truncated Panx1b protein-Confocal images of transiently transfected Panx1b $b^{+/+}$-EGFP (left panel) and Panx1b ${ }^{\Delta 11}$-DsRed-monomer (right panel) proteins in Neuro2a cells. Scale bar: $10 \mu \mathrm{m}$. (f) Panx1b immunoreactivity in the adult retina of TL fish. The section represents the retina at the contact point with the optic nerve $(\mathrm{ON})$. The closed triangle points at Panx1b staining in the inner plexiform layer (IPL). The open triangle represents Panx1b immunoreactivity in end-feet of Muller glia. The inset ( $\left.\mathbf{f}^{\prime}\right)$ shows GFAP-stained Muller glia in the same region of a consecutive slice of the retina indicated by an open triangle. (g) Open arrows point at Panx1b-positive Muller glia end 
feet. (h) Closed triangles point at Panx1b positive retinal ganglion cells. (i) Lack of significant Panx1b immunoreactivity in the adult panx $1 b^{-/-}$retina. (j) Control with 2 nd antibody only. Please note that the gain of the green channel in images $(\mathbf{i}, \mathbf{j})$ was enhanced to visualize the background staining. Abbreviations: WT, wild type TL; GCL, ganglion cell layer; IPL, inner plexiform layer; INL, inner nuclear layer; OPL, outer plexiform layer; ON, optic nerve. Scale bars: $\left(\mathbf{f}, \mathbf{f}^{\prime}\right)=100 \mu \mathrm{m} ;(\mathbf{g}, \mathbf{h})=25 \mu \mathrm{m}$; $(\mathbf{i}, \mathbf{j})=20 \mu \mathrm{m}$.

\subsection{Characterization of pan $x 1 b^{-/-}$Larvae}

The panx $1 b^{-/-}$survival rate was significantly lower than TL controls at $1 \mathrm{dpf}$ (values in $\%$ : TL, 80; panx $\left.1 b^{-/-}, 62.2 ; p=0.0062\right)$. Although the survival rate of panx $1 b^{-/-}$larvae compared to TL improved by day 6 (values in \%: TL, 83; panx1 $b^{-/-}, 87 ; p=0.538$; Figure 2a), this phenomenon was unusual. The visual inspection of the gross anatomy of larvae after hatching on 3dpf, showed that pan $\times 1 b^{-/-}$mutants developed a spectrum of morphological phenotypes from normal to malformed. Malformations included swimming bladder edema, ventricular hypertrophy, an irregularly shaped yolk sac, and abnormal spinal curvature in approximately $11 \pm 4 \%$ of mutants. Whether these malformations derived from abnormal development was not determined since larvae representing this spectrum of malformations could not survive beyond 5-6 dpf. Figure $2 \mathrm{~b}$ represents pan $\times 1 b^{-/-}$and TL control larvae of the F4 generation at $6 \mathrm{dpf}$. At this stage morphological malformations were not apparent. However, the head-to-tail size of $6 \mathrm{dpf}$ panx $1 b^{-/-}$larvae was significantly larger than the size of age matched TL controls (TL control $=3.83 \pm 0.27 \mathrm{~mm}$; panx $1 b^{-/-}=4.00 \pm 0.17$ $\mathrm{mm} ; p<0.0001$; for TL, $\mathrm{n}=60$; panx $1 b^{-/-}, \mathrm{n}=44$; Figure 2c). Adult pan $x 1 b^{-/-}$zebrafish were viable and fertile, with no apparent anatomical abnormalities. No gross morphologic changes to the eyes were observed. Furthermore, no significant reduction in the panx $1 b$ mRNA level was detected by RT-qPCR in $6 \mathrm{dpf}$ pan $x 1 b^{-1-}$ larvae. This indicated that the $11 \mathrm{nt}$ deletion in pan $x 1 b^{-/-}$RNA did not activate cytoplasmic RNA decay pathways like previously observed in the panx1 $b^{-/-}$mutant [19]. A compensatory regulation of the expression of the other three pannexin genes, panx1a, panx2, or panx3, was not detected (Figure 2d). A quantitative demonstration of the loss-of Panx1b protein expression in zebrafish tissues was not achieved. Several attempts to generate high-affinity polyclonal or monoclonal antibodies directed against both GST-Panx1b fusion proteins or synthetic peptides failed to generate a product fit for western blot analysis.

\subsection{Transcriptome Profiling of 6 dpf panx $1 b^{-/-}$Larvae}

The transcriptomes of panx $1 b^{-/-}$and TL larvae were compared at $6 \mathrm{dpf}$ following RNA-sequencing (NCBI Gene Expression Omnibus (GEO) database entry GSE181853). A total of 58,616 RNA transcripts matched the Ensembl GRCz11 reference genome (TL control, panx $\left.1 b^{-/-} ; \mathrm{n}=3\right) .38,017$ RNA transcripts with unique TranscriptID represented 25,592 proteins. Non-coding RNAs, antisense RNAs, lincRNAs, or annotated RNA transcripts which were not expressed in every sample were excluded from the next analysis steps. In panx $1 b^{-/-}$larva, 1213 RNA transcripts were downregulated, and 764 unique RNA transcripts were upregulated when the cut-off for the false discovery rate (FDR) was set to 0.05 , and the significance of expression regulation was defined as $p$-value $<0.001$. In the next step gene-specific RNA expression information was retrieved from the Zebrafish Information Network (ZFIN) database using the matching identifiers GeneID, gene name, and Transcript ID to compare all differentially regulated RNA transcripts to those previously described as expressed in the central nervous system (CNS) and the visual system. Sixty-two upregulated RNA transcripts and 92 downregulated RNA transcripts were matched based on GeneIDs to expression in the central nervous system (Figure 3a, left panel). Furthermore, 43 upregulated RNA transcripts and 77 downregulated RNA transcripts matched genes expressed in the visual system (Figure 3a, right panel). 
a)

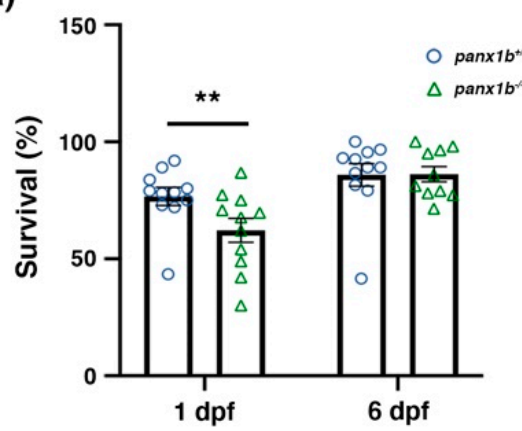

c)

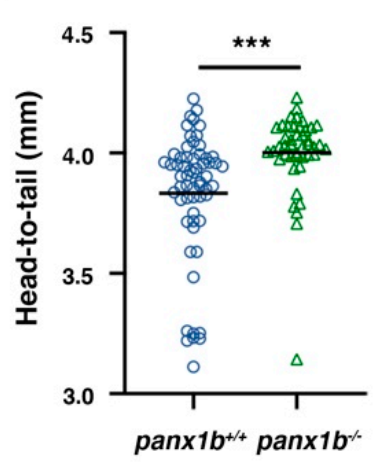

b)
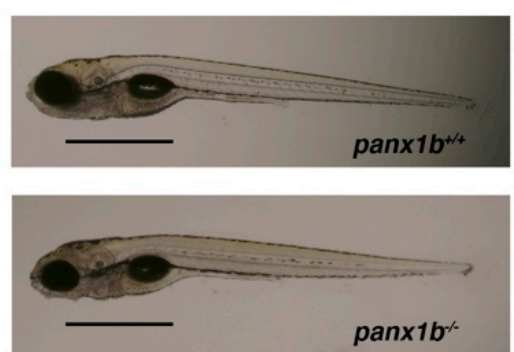

d)

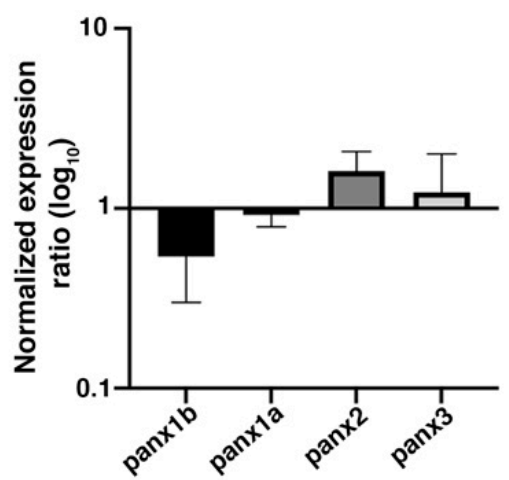

Figure 2. Primary characterization of $p a n \times 1 b^{-/-}$larvae. (a) Survival rate at $24 \mathrm{~h}$ and six days post-fertilization (1 dpf, $6 \mathrm{dpf}$ ). (b) Morphology of age-matched TL control and panx $1 b^{-/-}$larvae (at 6dpf) showing regular anatomical features. Scale bar $=100 \mu \mathrm{m}$. (c) Head-to-tail size measurement of panx $1 b^{-/-}$and control TLs (6 dpf). (d) RT-qPCR analysis of pannexin gene expression in 6dpf larvae. Significance: ${ }^{* *} p<0.01$ and ${ }^{* * *} p<0.001$; nd: Not detected. Error bars $=$ SEM.

To describe the impact of the loss of Panx $1 \mathrm{~b}$ on the transcriptome of knockout larvae, an AmiGO2 analysis (http:/ / amigo.geneontology.org/amigo/landing, 20 September 2021) using the differently regulated RNA transcripts GeneIDs was performed. The analysis delivered enriched Gene Ontology (GO) terms representing significantly enriched biological processes (Table 1). The most significantly enriched biological processes (cut-off: FDR < $0.05, p$-value $<0.001)$ represented the regulation of primary and macromolecules metabolic processes (Figure $3 \mathrm{~b}$ ). Downregulated genes represented several biological processes, including the circadian regulation of gene expression, RNA processing, and G-protein coupled receptors signaling pathways (Figure $3 \mathrm{~b}$ ).

The downregulation of circadian clock genes observed in the RNAseq data (cut-off: $p$-value < 0.001; FDR 0.05) were further validated by RNA-qPCR (cut-off: $p$-value $<0.05$ ). The genes selected are known to drive the rhythmic 24-h expression patterns of core clock components. Here, the downregulation detected by RNA-seq analysis was confirmed (Figure 3c, Table 2). The modulation of the circadian clock pathway in the absence of Panx1b suggests a mechanism that could affect physiological functions such as sleepwakefulness cycle, locomotor activity, or metabolic processes in $6 \mathrm{dpf}$ old larvae by altering the circuitry which connects retina outputs with midbrain nuclei and the optic tectum (Figure 3d,e). 
a)
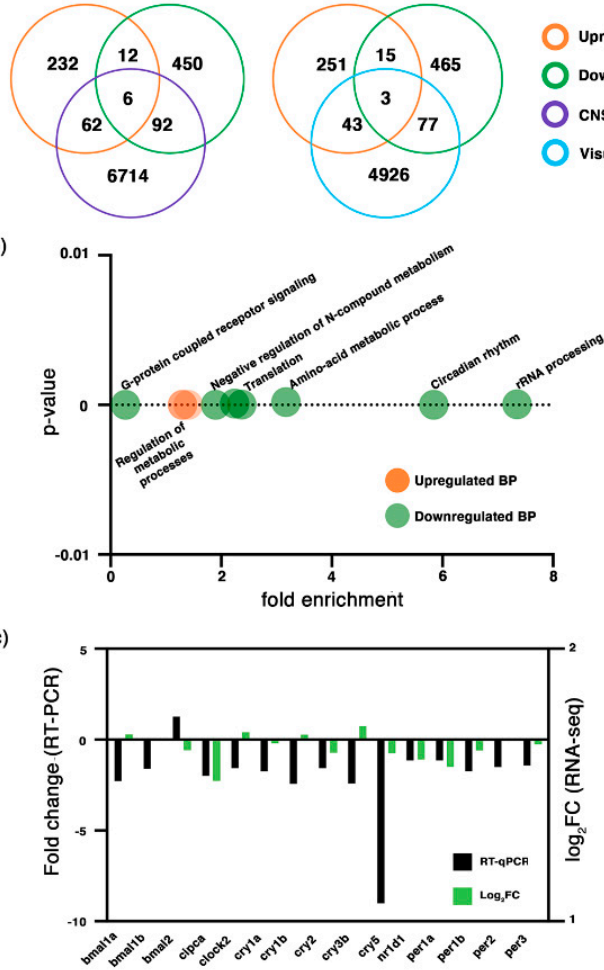

d)

Downregulated genes

cns

Visual system

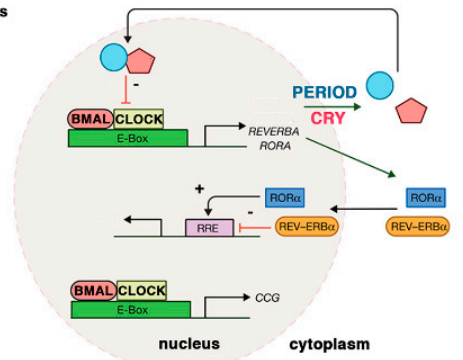

e)

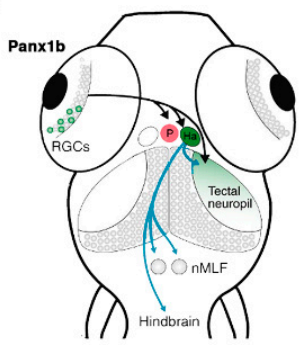

Figure 3. RNA-seq analysis of $6 \mathrm{dpf}$ pan $x 1 b^{-/-}$larvae. (a) Comparison of differentially regulated RNA transcripts against two categories: central nervous system (CNS) and the visual system. (b) GO annotation of RNA-seq data in terms of biological process (BP): the upregulated RNA transcripts were enriched in the regulation of metabolic processes, whereas the downregulated genes were annotated for RNA processing, circadian rhythms, amino-acid metabolic process, translation, negative regulation of nitrogen $(\mathrm{N})$ compounds metabolism, and G-protein coupled receptor signaling. (c) Validation of RNA-seq data by RT-qPCR. The significant downregulation of cry1, cry5, bmal1a, bmal1b, and clock2 genes in $6 \mathrm{dpf}$ panx $1 b^{-/-}$larvae was confirmed by RT-qPCR in $\mathrm{n}=3$ independent replicates. (d) Cartoon illustrating the network of circadian clock genes differently regulated in pan $x 1 b^{-/-}$larvae. Regulated genes in bold. (e) Illustration of the connection of the inner retina with optic tectum, habenula (Ha), and pretectum $(p)$ conferring light sensitivity and circadian rhythmicity, and descending control of locomotion. Abbreviation: nMLF, nucleus of the medial longitudinal fasciculus.

Table 1. GO annotation for regulated biological process.

\begin{tabular}{|c|c|c|c|c|}
\hline Biological Process (Up) & Danio Rerio (REF) \# & Upload \# & Fold Enrichment & $p$-Value \\
\hline $\begin{array}{l}\text { Regulation of primary metabolic } \\
\text { process (GO:0080090) }\end{array}$ & 4132 & 170 & 1.4 & 0.0000062 \\
\hline $\begin{array}{l}\text { Regulation of nitrogen compound } \\
\text { metabolic process (GO:0051171) }\end{array}$ & 4076 & 167 & 1.39 & 0.000009 \\
\hline $\begin{array}{l}\text { Regulation of macromolecule } \\
\text { metabolic process (GO:0060255) }\end{array}$ & 4368 & 178 & 1.39 & 0.00000623 \\
\hline Biological Process (Down) & Danio Rerio (REF) \# & Upload \# & Fold Enrichment & $p$-Value \\
\hline $\begin{array}{l}\text { cleavage involved in rRNA processing } \\
\text { (GO:0000469) }\end{array}$ & 26 & 8 & 7.35 & 0.0000474 \\
\hline $\begin{array}{l}\text { circadian regulation of gene } \\
\text { expression (GO:0032922) }\end{array}$ & 45 & 11 & 5.84 & 0.0000119 \\
\hline $\begin{array}{l}\text { cellular modified amino acid } \\
\text { metabolic process (GO:0006575) }\end{array}$ & 113 & 15 & 3.17 & 0.000199 \\
\hline
\end{tabular}


Table 1. Cont

\begin{tabular}{|c|c|c|c|c|}
\hline Biological Process (Up) & Danio Rerio (REF) \# & Upload \# & Fold Enrichment & $p$-Value \\
\hline mRNA processing (GO:0006397) & 332 & 33 & 2.37 & 0.0000185 \\
\hline translation (GO:0006412) & 320 & 30 & 2.24 & 0.0000975 \\
\hline $\begin{array}{l}\text { negative regulation of nitrogen } \\
\text { compound metabolic process } \\
\text { (GO:0051172) }\end{array}$ & 756 & 60 & 1.9 & 0.00000729 \\
\hline $\begin{array}{c}\text { G protein-coupled receptor signaling } \\
\text { pathway (GO:0007186) }\end{array}$ & 1134 & 13 & 0.27 & 0.00000000543 \\
\hline
\end{tabular}

Abbreviation: REF, number of genes in category in reference genome. Upload, number of genes in category identified in the uploaded gene list.

Table 2. RT-qPCR results for transcripts associated with the circadian clock pathway.

\begin{tabular}{ccccc}
\hline Gene & $\begin{array}{c}\text { RT-qPCR } \\
\text { Expression (REST) }\end{array}$ & SEM (REST) & $p$-Value (REST) & Result \\
\hline bmal1a & -2.277 & 0.050 & 0.005 & Down \\
\hline bmal1b & -1.609 & 0.053 & 0.019 & Down \\
\hline bmal2 & 1.273 & 0.135 & 0.246 & \\
\hline cipca & -1.988 & 0.060 & 0.055 & Down \\
\hline clock2 & -1.568 & 0.063 & 0.017 & Down \\
\hline cry1a & -1.749 & 0.109 & 0.004 & Down \\
\hline cry1b & -2.43 & 0.086 & 0.002 & Down \\
\hline cry2 & -1.569 & 0.073 & 0.058 & \\
\hline cry3b & -2.42 & 0.052 & 0.11 & \\
\hline cry5 & -9.002 & 0.033 & 0.0012 & \\
\hline nr1d1 & -1.142 & 0.065 & 0.279 & \\
\hline per1a & -1.142 & 0.062 & 0.451 & \\
\hline per1b & -1.732 & 0.159 & 0.245 & 0.154 \\
\hline per2 & -1.503 & 0.082 & 0.289 & \\
\hline per3 & -1.422 & 0.184 & & \\
\hline & & & \\
\hline
\end{tabular}

\subsection{Loss of Panx1b Affected Visually Guided Locomotor Activities of Larvae}

Physiological, molecular, and behavioral studies have demonstrated robust circadian rhythmicity in the zebrafish based on the visual system [22]. As the transcriptome data analysis provided evidence that the lack of Panx $1 \mathrm{~b}$ caused changes in both the visual and the circadian clock systems, three types of visually guided locomotion-based tests, e.g., (1) locomotion in a stimulus-free environment, (2) visual-motor response (VMR) [23], and (3) optomotor response (OMR) [24], were investigated.

The baseline locomotor performance of the panx $1 \mathrm{~b}^{-/-}$and TL larvae were compared under constant light (Light-ON) or dark (Light-OFF) conditions. Under the Light-ON condition, both TL controls and panx $1 \mathrm{~b}^{-/-}$swam longer distances and more rapidly than during the Light-OFF condition. Both genotypes displayed similar locomotor activity in Light-ON (Figure 4a). The average of the distance traveled $\left(\right.$ pan $x 1 b^{+/+}=154.38$, panx $1 b^{-/-}$ $=158.90,95 \%$ Confidence Interval $(\mathrm{CI})=-27.14-36.18, \mathrm{t}=0.286, \mathrm{df}=52.295, p$-value $=$ 0.7758 ; for $\mathrm{n}=30$ larvae) and the velocity $\left(\right.$ panx $1 b^{+/+}=2.69$, panx $1 b^{-/-}=2.86,95 \% \mathrm{CI}$ $=-0.33-0.68, \mathrm{t}=0.686, \mathrm{df}=50.325, p$-value $=0.496$; for $\mathrm{n}=30$ larvae) were comparable between both cohorts. Both groups showed a similar preference for swimming in the outer zone relative to the central "open space" area of the well (Figure 4a; well illustration). Also, no significant difference in average distance travelled in the central zone (bordered with a 
red rectangle in the well illustrations) was detected between genotypes $\left(\right.$ pan $x 1 b^{+/+}=13.03$, panx $1 b^{-/-}=9.49,95 \% \mathrm{CI}=-1.19-8.27, \mathrm{t}=1.508, \mathrm{df}=42.89, p$-value $=0.13 ; \mathrm{n}=30$ larvae $)$.

a)

Average Travelled Average Velocity

Distance
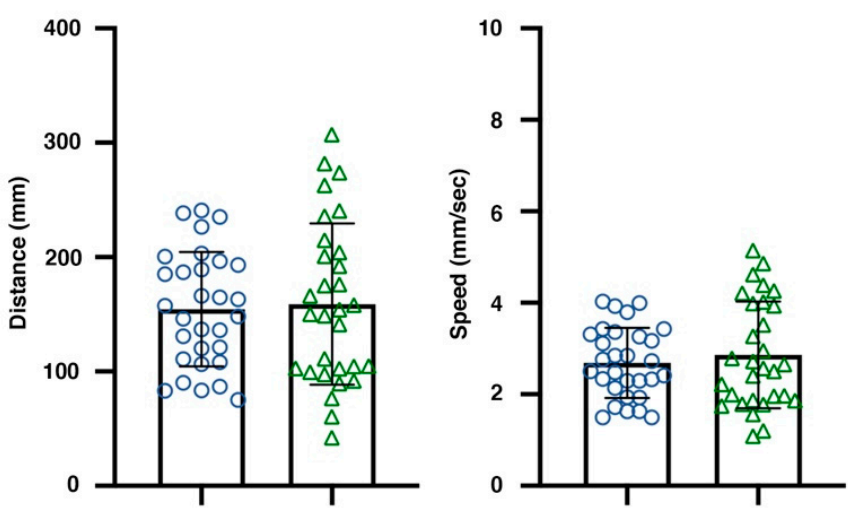

b)
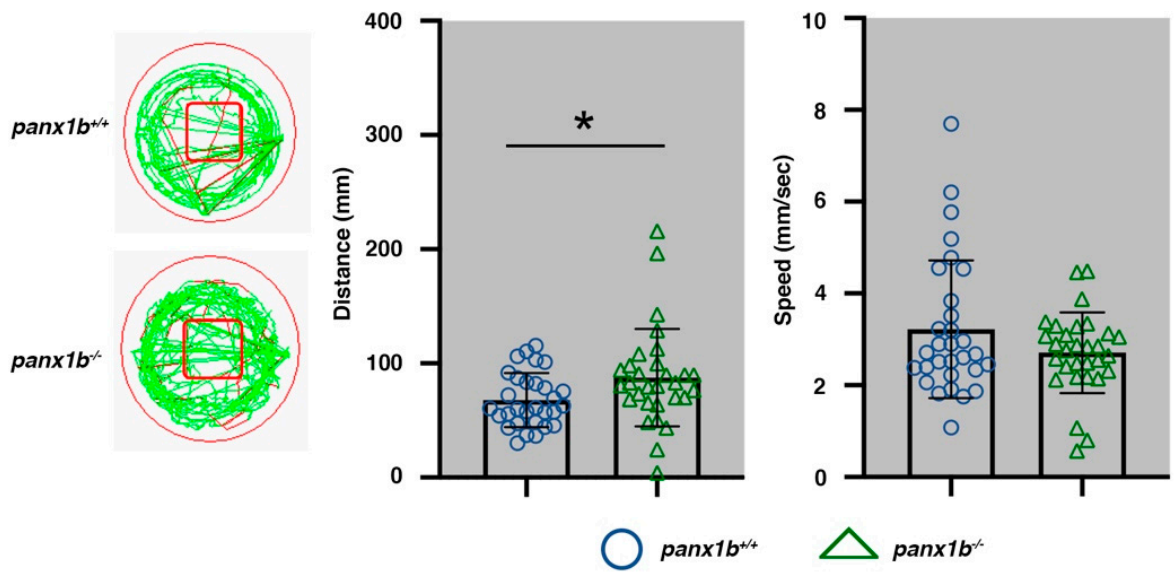

Figure 4. Locomotor activity in Light-ON and Light-OFF conditions. Locomotion was video tracked for $60 \mathrm{~min}$ in (a) Light-ON and (b) Light-OFF conditions. The wells on the left show examples of the locomotion patterns of panx $1 b^{-/-}$and panx $1 b^{+/+}$(TL control) larvae at $6 \mathrm{dpf}$. Medium $(<20 \mathrm{~mm} / \mathrm{s}$ ) or high-speed movements $(>20 \mathrm{~mm} / \mathrm{s})$ were visualized with green and red colors. The red square marks the region of interest used for assessment of the average distance travelled in the central zone. Graphs demonstrate the averaged traveled distance (in $\mathrm{mm}$ ) and the average velocity $(\mathrm{mm} / \mathrm{s}$ ) of $\mathrm{n}=30$ larvae for each genotype. A Welch's $t$-test was used for statistical comparison of groups. Significance: ${ }^{*}=p$-value $<0.05$. Error bars $=$ SEM.

During the Light-OFF phase, panx $1 b^{-/-}$larvae were more active than TL controls. They swam significantly longer distances $\left(\right.$ panx $1 b^{+/+}=67.89$, pan $x 1 b^{-/-}=87.38,95 \%$ CI $=1.55-37.42, \mathrm{t}=2.189, \mathrm{df}=45.194, p$-value $=0.0338 ; \mathrm{n}=30$ larvae) although with similar velocity $\left(\right.$ panx $1 b^{+/+}=3.21$, panx $1 b^{-/-}=2.70,95 \% \mathrm{CI}=-1.14-0.12, \mathrm{t}=-1.609, \mathrm{df}=46.751$, $p$-value $=0.1142 ; \mathrm{n}=30$ larvae) as TL controls (Figure $4 \mathrm{~b}$ ). No difference was observed in the preference of both genotypes to stay close to the wall of the well during the Light-OFF period (Figure $4 \mathrm{~b}$; well illustration; the average distance travelled in the central zone for panx $1 b^{+/+}=4.92$, panx $1 b^{-/-}=5.05,95 \% \mathrm{CI}=-3.19-2.92, \mathrm{t}=-0.087, \mathrm{df}=52.46, p$-value $=$ $0.93 ; \mathrm{n}=30$ larvae).

Next, the visual-motor response (VMR) assay was used to demonstrate the reaction of pan $\times 1 b^{-/-}$larvae to sudden light changes. A principal component analysis (PCA) demonstrated that the two principal components PC1 and PC2 captured more than $65.5 \%$ and $29.5 \%$ of the data variance (Figure $5 \mathrm{a}$ ). The total activity duration (TAD; in red) had 
the most significant contribution to the observed variability in $\mathrm{PC} 1$ among seven variables tested (i.e., count and duration of freeze, bouts, and bursts of activity, plus total activity duration) (Figure 5b).

a)

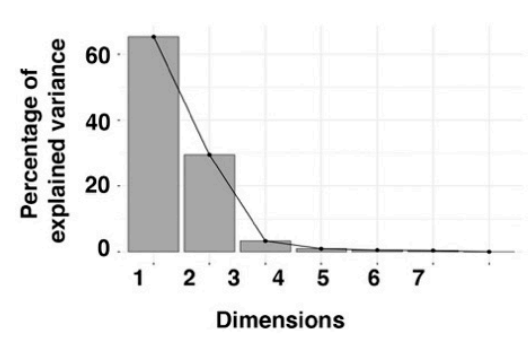

c)

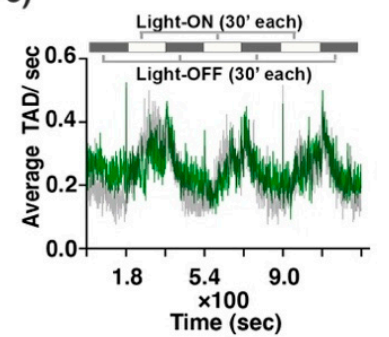

b)

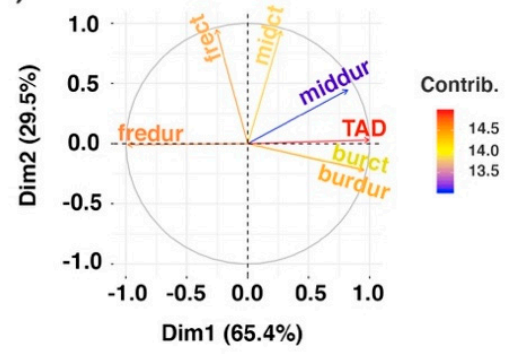

d)

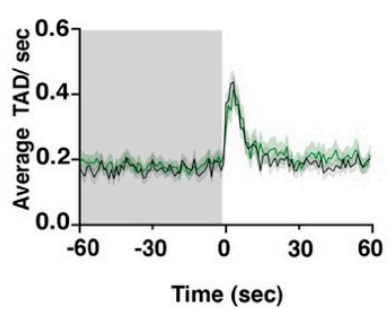

e)

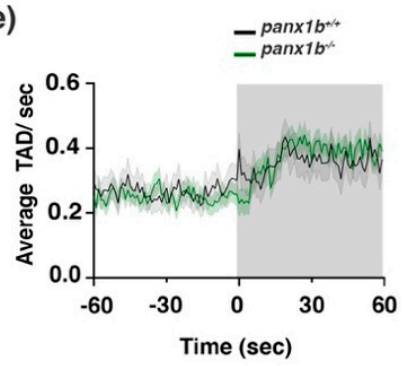

Figure 5. Visual-motor motor response (VMR) changes in panx $1 b^{-/-}$larvae at $6 \mathrm{dpf}$. (a) Principal component analysis (PCA) transforming the VMR multidimensional data. The scree plot shows that Dimensions 1 and 2 capture more than $65.4 \%$ and $29.5 \%$ of the data variance. (b) The variable correlation plot represented the coordinates of the variables in the first two dimensions. The variables were colored from blue to red as their contribution to PCs increases. Total activity duration (TAD; in color red) showed the highest contribution to the variability in Dimension 1 and was chosen to visualize differences between genotypes. (c) The outline of the experimental paradigm is shown on top. The line graph shows the average TAD of panx $1 b^{-/-}$and panx $1 b^{+/+}$(TL) larvae from a representative test with $n=24$ larvae for each genotype. The activity was defined as the fraction of frames per second that a larva spent swimming (see methods for the detailed information). (d,e) The results for average Light-ON and Light-OFF VMR are shown from $1 \mathrm{~min}$ before the light switch to $1 \mathrm{~min}$ after the light switch. The color ribbons surrounding the average activity line graph correspond to 1 S.E.M. The values are the average of the second trial from four independent tests with $n=48$ larvae for each genotype. The Light-ON and Light-OFF periods are indicated by white and black bars at the top of the panels. The "nparcomp" analysis was used for multiple comparisons and simultaneous confidence intervals.

The variable TAD was chosen to determine the VMR differences between both genotypes. The larval VMR differed from TL controls when the panx1b gene was ablated as indicated by the mean larval activity during 3 cycles of light onset (Light-ON) and lightoffset (Light-OFF) (Figure 5c). While the mutants' motor activity during the Light-ON phases was markedly lower than TLs, they had comparable activity levels during the dark periods. A pairwise non-parametric $t$-test (nparcomp package; R) quantified larval activity during the following time periods: $-60-0 \mathrm{~s}$ (i.e., before light change), $0-1 \mathrm{~s}$ (i.e., at the light change stimulus) and 1-60 s (i.e., after light change) (Table 3). For the 1 min period before the Light-ON stimulus ( $-60-0 \mathrm{~s})$, there was a statistical difference in the activity between TL and panx $1 b^{-/-}$(effect estimator: 0.5; adjusted $p$-value (padj) 0.001, for $\mathrm{n}=48$ larvae), in which the activity level of panx $1 b^{-/-}$before the light change was greater than that of TL larvae. At the dark-light transition (Light-ON; 0-1 s), a synchronous increase in locomotor activity was observed in both TL and panx $1 b^{-/-}$groups (effect estimator: 0.6 , padj $=0.08$, for $n=48$ larvae), which was followed by a rapid activity decline to a baseline level during the subsequent light period (in 1-60 s, effect estimator: 0.5 , adjusted padj $=0.7$. for $n=48$ larvae; Figure 5d). 
Table 3. Report of the VMR "nparcomp" analysis from four independent tests with a total of $n=48$ larvae for each genotype.

\begin{tabular}{|c|c|c|c|c|c|c|c|}
\hline & & TL & & Panx1b $^{-1}$ & & & \\
\hline Stimulus & Time Bin & $\begin{array}{c}\text { Average } \\
\text { TAD/s }\end{array}$ & S.E.M & $\begin{array}{c}\text { Average } \\
\text { TAD/s }\end{array}$ & S.E.M & $\begin{array}{l}\text { Effect Es- } \\
\text { timator } \\
\text { EE }\end{array}$ & $\begin{array}{c}\text { Adjusted } \\
p \text {-Value }\end{array}$ \\
\hline \multirow[t]{3}{*}{$\begin{array}{l}\text { Light- } \\
\text { ON }\end{array}$} & Before (60-0 s) & 0.17 & 0.13 & 0.18 & 0.14 & 0.48 & 0.00 \\
\hline & AT (0-1 s) & 0.38 & 0.19 & 0.33 & 0.22 & 0.57 & 0.08 \\
\hline & After (1-60 s) & 0.21 & 0.15 & 0.23 & 0.20 & 0.50 & 0.70 \\
\hline \multirow[t]{3}{*}{$\begin{array}{l}\text { Light- } \\
\text { OFF }\end{array}$} & Before $(60-0 \mathrm{~s})$ & $0 . .27$ & 0.27 & 0.25 & 0.19 & 0.53 & 0.00 \\
\hline & AT (0-1 s) & 0.36 & 0.31 & 0.24 & 0.24 & 0.67 & 0.00 \\
\hline & After (1-60 s) & 0.36 & 0.33 & 0.37 & 0.23 & 0.49 & 0.06 \\
\hline
\end{tabular}

At the light-dark transition, a synchronous and abrupt increase in motor activity was observed in TL control larvae. Following this trend, larval motor activity remained elevated for several minutes before slowly declining within 10-15 min, until swim activity fell below the baseline activity level in Light-ON conditions (Figure 5e). Interestingly, panx $1 b^{-/-}$ larvae responded to the dark differently compared to control TLs. For the $1 \mathrm{~min}$ period before the Light-OFF stimulus (-60-0 s), pan $\times 1 b^{-/-}$larvae activity was markedly lower than the activity of TLs (effect estimator: 0.5 , padj $<0.0001$, for $n=48$ larvae). Notably, the peak response to the abrupt loss of illumination was absent in mutants ( $0-1 \mathrm{~s}$; effect estimator: 0.7 , padj $<0.0001$, for $\mathrm{n}=48$ larvae). Rather than sharply increasing motor activity, mutants failed to respond to the Light-OFF stimulus for several seconds, indicated by periods of no activity. Then, activity gradually increased to levels comparable to TLs in the subsequent dark period. For the $1 \mathrm{~min}$ period after the Light-OFF stimulus, no significant differences between TL and the mutant's activity were observed (1-60 s; effect estimator: 0.49 , padj $=0.06$, for $\mathrm{n}=48$ larvae (Figure 5e). The results showed that panx $1 b^{-/-}$ larvae can detect and respond to light. However, their peak response to a dark pulse was abolished, which suggested that Panx1b in the retina functions in detecting light decrement and eliciting the corresponding swimming response in larval zebrafish.

Finally, the OMR test was used to assess the innate behavior of zebrafish to follow visual motion in the surrounding environment to stabilize their location or course of movement $[25,26]$. The optimal stimulus parameters for distinguishing mutants from TL control larvae were found by presenting moving gratings at three spatial frequencies (SF; $64,128$, and 256 pixels/cycle), and two velocities (72 and $144 \mathrm{deg} / \mathrm{s})$, and two contrast levels of $(10,100$ percent). Figure 6 shows the percentage of positive response (PPR) of 40 larvae after $90 \mathrm{~s}$ of exposure to grating motion towards alternating right and left stimuli. For all combinations of SFs, velocities, and contrasts, the percentage of panx1b $1 b^{-/-}$larvae responding to the stimulus was lower than that in the TL control group. A bias was detected when the direction of moving stripes was set towards the left side. 
a)

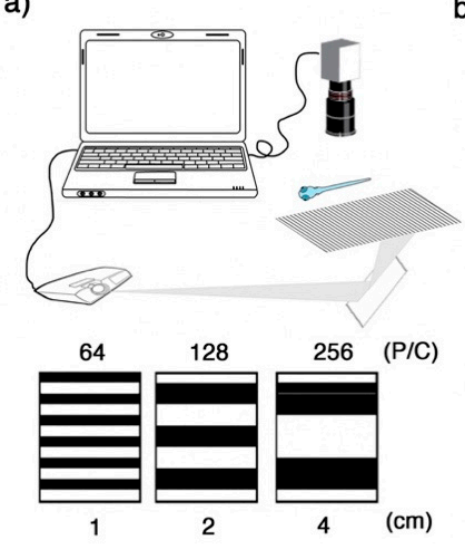

b)

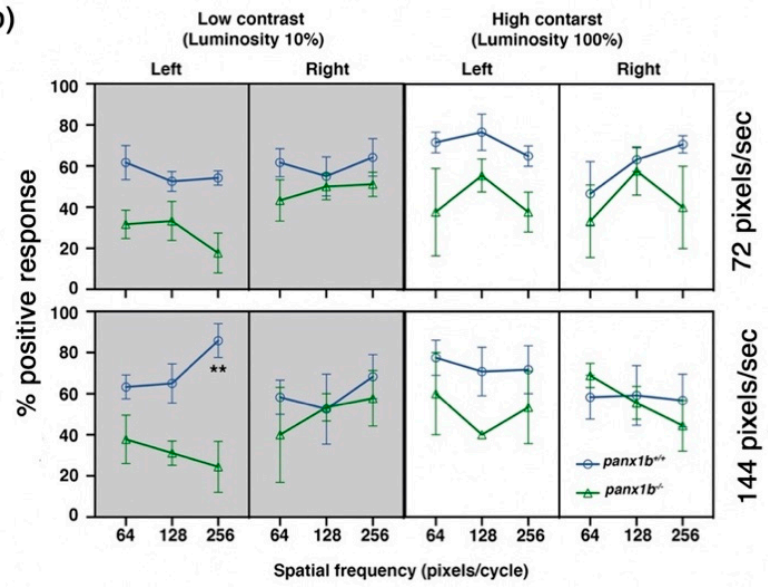

Figure 6. Optomotor response (OMR) declines in the absence of functional Panx1b. (a) The OMR setup. Three spatial frequencies at two different speed rates and two luminosity levels were used to assess larval zebrafish's visual acuity. $\mathrm{P} / \mathrm{C}=$ pixel/cycle $(\mathbf{b})$ The percentage of positive response $(\%$ PPR) explains the average number of larvae that responded to a particular setting. The PPR values for each setting are the average of four tests \pm SEM. In all tested settings, pan $x 1 b^{-/-}$were able to elicit an appropriate response, as observed in TL controls. However, their visual acuity was lower than controls when the direction of motion was towards the left. The difference between genotypes' PPR for the left-ward motion became very significant at a spatial frequency of 256, with a speed of 144 , and a low contrast setting $(\mathrm{n}=40)$. The " $1 \mathrm{~m}$ " and the model statistical "summary" functions were used to fit a regression model. The significant differences were calculated using the "TukeyHSD" function in R. Significance: ${ }^{* *} p$-value $<0.01$. Error bars $=$ SEM.

At low contrast level (10\%; left panels), panx $1 b^{-/-}$larvae were markedly distinct from TL controls when tested with left-ward moving stripes at a spatial frequency of 256 pixels / cycle and a speed of 144 pixels/s. The PPR of TL and panx $1 b^{-/-}$larvae were $85.8 \pm 16.4 \%$ and $24.4 \pm 21.4 \%$, respectively ( $p$-value $=0.0012 ; n=40)$. For the low-spatial frequencies (i.e., 64 and 128 pixels/cycle), both genotypes swam most often in the direction of the moving stimulus when tested with a velocity of 72 or 144 (deg/s). No significant differences were observed within or between groups. However, when spatial frequencies were increased from 128 to 256 pixels/cycle, the average PPR was augmented at high velocities in TL controls. This result was in line with the previous reports on the larval zebrafish visual acuity peaking at the spatial frequency of 256 (pixels/cycle), and at a speed of 144 (deg/s) [27]. A similar increase in the larval response was observed in mutants only when larvae were exposed to the rightward moving grating. Panx $1 b^{-/-}$larvae showed a significant impairment for following the leftward moving stripes at the same combination of SF and velocity. The data suggested that the visual acuity of panx $1 b^{-/-}$larvae was compromised in low contrast conditions, which was in line with the aforementioned VMR result in the dark environment. Furthermore, the peak response deficiency, observed at SF of 256 pixels / cycle and speed of 144 pixels/s, for the leftward direction provided first evidence that Panx $1 b$ could be involved in a directional tuning impairment in pan $x 1 b^{-/-}$ larvae. This advocates for a role of Panx1b in the processing of motion direction signals.

On the other hand, at high contrast level (100\%), none of the tested combinations of SFs and velocities elicited a statistically significant difference between mutants' and TLs' OMRs (Figure 6, right panels). The pairwise comparisons for each spatial frequency revealed no statistically significant differences within groups for either velocity. This outcome suggested that in a high contrast condition, when the environment was bright and the edges of objects were well defined, the visual acuity of panx $1 b^{-/}-$larvae was normal ( $p$-values: see Table 4). 
Table 4. The multivariate comparisons of OMR between TL control and pan $x 1 b^{-/-}$larvae.

\begin{tabular}{clcccccc}
\hline \multicolumn{2}{c}{ Contrast Levels } & \multicolumn{3}{c}{ Low (10\%) } & \multicolumn{4}{c}{ High (100\%) } \\
\hline \multirow{2}{*}{$\begin{array}{c}\text { Speed } \\
\text { (pixels/s) }\end{array}$} & Direction & \multicolumn{4}{c}{ Spatial Frequencies (pixels/cycles) } \\
\cline { 2 - 8 } & & 64 & 128 & 256 & 64 & 128 & 256 \\
\hline \multirow{2}{*}{72} & Leftward & 0.061 & 0.51 & 0.16 & 0.23 & 0.22 & 0.22 \\
\cline { 2 - 8 } & Rightward & 0.52 & 0.77 & 0.44 & 0.89 & 0.8 & 0.33 \\
\hline \multirow{2}{*}{144} & Leftward & 0.22 & 0.13 & 0.0012 & 0.63 & 0.26 & 0.66 \\
\cline { 2 - 8 } & Rightward & 0.97 & 0.97 & 0.97 & 0.65 & 0.99 & 0.77 \\
\hline
\end{tabular}

\section{Discussion}

The localization of Panx1b in the inner retina and the ganglion cell layer offers opportunities to study pannexin functions in the retinal output pathway and in visual behaviors. Here, transcription activator-like effector nucleases (TALEN) introduced an 11-bp deletion in exon 4 of the panx $1 b$ gene causing a loss-of function mutation in the Panx $1 b$ protein. The strategy used is comparable to the conditional gene targeting of protein coding exons 3 and 4 in a Panx1 knockout mouse model $[10,28]$ and to our other panx $1 a^{-/-}$and panx $1 b^{-/-}$ zebrafish models $[18,19]$. Like adult pan $\times 1 a^{-/-}$the panx $1 b^{-/-}$zebrafish were viable and fertile, with no apparent anatomical abnormalities or visible morphologic changes to the eyes interfering with the study design.

At $6 \mathrm{dpf}$ the visual system and visually guided locomotor activity of larvae is well established [25]. This allowed to test three types of visually guided behaviors. The absence of Panx $1 \mathrm{~b}$ impaired both visually guided locomotor activities and the visualmotor response (VMR) of larvae in the dark differently to the changes when Panx1a is lost [19]. The pattern of immediate freeze followed by partial recovery following the LightOFF stimulus was distinct from the sustained reduction in locomotion seen in panx1 $a^{-1-}$ larvae [19]. Supporting evidence for a function in OFF-type retinal ganglion cells (RGCs) derives from patterned electroretinograms (PERG) and patch-clamp recordings of mice with targeted ablation of the Panx1 gene [29]. The response of OFF-type RGCs in mice and our data in the zebrafish let us conclude that the immediate response to sudden darkness could be associated with a similar disruption of the inner nuclear layer circuits, where Panx $1 b$ is localized [16].

The third behavioral test, the optomotor response (OMR) assay, detects changes to swimming posture testing the ganglion cells' function [26,30-32]. Without prior training and while larvae were freely moving, we showed robust OMR at $6 \mathrm{dpf}$ in line with other studies presenting this response in larvae as early as $5 \mathrm{dpf}[26,33]$. Here, we demonstrate that Panx $1 b$ affects the optic flow's direction-selectivity, affecting the left-ward direction of motion at high spatiotemporal frequencies and low contrast conditions.

Presently, we can only speculate about how Panx1b affects the direction of motion detection tested by OMR. Future research must explain whether a similar right-ward motion detection change exists, and whether Panx1a or a connexin protein could play a role in it. In both zebrafish and in humans, motion detection is dominated by a luminance channel, which pools red and green cone signals [34]. However, RNA-seq data exclude the differential expression of red-or green-sensitive opsins, which differs to the upregulation of blue and UV-sensitive opsins and genes representing the phototransduction cascade found in panx1 $1 a^{-/-}$[19]. While this observation does not conclusively rule out altered photoreceptor function, roles of Panx1b are more likely to affect the inner retina based on the localization in ganglion cells.

In the inner retina direction-selective ganglion cells (DSGCs) process and encode the presence, time, and the direction of motion [32]. Zebrafish RGCs send a diverse and highly regionalized time and spectral code to the brain [35]. The direction of motion is encoded by three direction-selective subtypes of ganglion cells tuned to upward, downward, and caudal-to-rostral motion [36]. Furthermore, the direction tuning of multiple subtypes of 
DSGCs depends on the light level [37]. The direction selectivity of subpopulations of ONOFF DSGCs in mammalian models requires electrical coupling by gap junctions [38-40], striking a balance between improving the detection of motion in dimly lit conditions against a cost to the accuracy of direction estimation [41]. As the OMR deficiency in the absence of Panx $1 \mathrm{~b}$ occurred only with the left-ward motion at low light conditions, it is intriguing to speculate whether Panx $1 \mathrm{~b}$ channels located in the inner plexiform layer play similar roles or synergize with connexins in broadening direction tuning at low light levels in specific DSGCs subtypes.

Astrocytes can modulate the activity of neurons in vivo, affecting directly information processing and suppressing motor output in the OMR test [42]. Astrocytes are also a main source of extracellular purines such as ATP and adenosine [43,44]. In rodents Panx1 is a major conduit of non-vesicular ATP release into the extracellular medium [45,46], and astrocytes release ATP in a circadian manner [47]. The localization of Panx1b in Muller glia end feet is close to the axonal output from ganglion cells and the retinal vasculature. In our opinion, a hypothetic model based on a photoperiodic ATP release from Muller glia in the proximity of retinal ganglion cells is attractive in explaining the observed behavioral phenotypes in the zebrafish, or the regulation of non-image forming processes such as sleep-wakefulness, which has been demonstrated in Panx1 mouse models [48,49]. We propose a role of Panx $1 \mathrm{~b}$ in regulating clock-gene mediated heightened retinal sensitivity, which improves luminance detectability. This role fails to function properly in $p a n \times 1 b^{-/-}$ larvae, leading to a diminution of the Light-OFF stimulus response.

To the best of our knowledge, the neofunctionalization of Panx ohnologs in the fish add a new twist to the expanding repertoire of Panx1 functions. The results presented indicate that lack of Panx1b compromises the final output of luminance and direction of motion detectors. Also, mutant larvae show a deficiency in following leftward direction of motion in low light conditions. The observed misalignment of circadian clock system seems to disrupt synchronization of behavioral rhythms with the circadian light-dark cycle in the absence of Panx1b. The principal findings in the zebrafish offer opportunities for studies on the Panx $1 \mathrm{~b}$ association with the circadian clock pathway in a diverse array of biological processes beyond the retina, such as sleep/wakefulness, or metabolism.

\section{Materials and Methods}

Experimental Animals-All zebrafish (Danio Rerio) of strain Tupfel long fin (TL) were maintained in a recirculation system (Aquaneering Inc., San Diego, CA) at $28^{\circ} \mathrm{C}$ on a $14 \mathrm{~h} \mathrm{light} / 10 \mathrm{~h}$ dark cycle. All animal work was performed at York University's zebrafish vivarium and in S2 biosafety laboratory in accordance with the Canadian Council for Animal Care guidelines after approval of the protocol by the Animal Care Committee (GZ: 2020-7-R3).

Generating panx $1 b$ knockout zebrafish-Potential TALENs target sites were identified using Mojo Hand software (http:/ / talendesign.org, 20 September 2020) [50]. TALENs targeted exon 4 of panx1b (NM_001100030.2). The following criteria satisfied the TALEN design: TALENs target sites were 15-17 bases long with an initial $5^{\prime} \mathrm{T}$ nucleotide to the TALE domain. The spacer length was restricted to $15-16$ base pairs. Target sites with a unique restriction enzyme sequence located in the middle of the spacer sequence were selected to simplify screening for insertion-deletion (indel) mutations. The specificity of selected TALENs target sequences was determined using the BLAST interface built into the Mojo Hand software and by a NCBI BLAST search.

The TALEN constructs were synthesized in Dr. Stephen Ekker's lab (Mayo Clinic Cancer Center, Rochester, MN, USA). TALEN assemblies of the repeat-variable di-residues (RVD-containing repeats) were conducted using the Golden Gate approach [51]. pT3TSGoldyTALEN expression vectors [20,52]. Plasmids were linearized with the SacI restriction endonuclease (Thermo Fisher Scientific, Waltham, MA, USA) for $15 \mathrm{~min}$ at $37^{\circ} \mathrm{C}$ and used as templates for in vitro transcription. Capped cRNAs were synthesized from TALEN pairs mixed 1:1 using the mMESSAGE mMACHINE T3 Transcription kit (Life Technologies, 
Mississauga, ON, Canada) and purified using the Oligotex mRNA Mini Kit (Qiagen Inc., Toronto, ON, Canada). TALEN cRNAs were diluted in DNase/RNase-free water (Life Technologies) to the final concentration of $1 \mu \mathrm{g} / \mu \mathrm{L}$ and stored at $-80^{\circ} \mathrm{C}$ before microinjection.

One-cell stage zebrafish embryos were microinjected with TALEN cRNAs pair at a dosis of $25 \mathrm{pg} / \mathrm{nL}$. Genomic DNA (gDNA) was extracted from injected embryos at $4 \mathrm{dpf}$ to examine the TALEN mutagenesis efficiency. Individual larvae were incubated in $100 \mathrm{mM}$ $\mathrm{NaOH}$ at $95^{\circ} \mathrm{C}$ for $15 \mathrm{~min}$. After cooling to room temperature, one-tenth of the $1 \mathrm{M}$ Tris ( $\mathrm{pH}$ 8.0) volume was added to the extracts to neutralize the $\mathrm{NaOH}$. Finally, 1 volume TE buffer $\mathrm{pH} 8.0$ was added, and gDNAs were stored at $-20^{\circ} \mathrm{C}$. PCR was used as a screen to detect a small indel mutations followed by HindIII (for panx $1 b$ ) restriction enzyme (RE) digests. PCR primers for genotyping: 5'-TTGGCGTCGGCAAACAGTGG-3'; reverse, 5'-GGCGACGAGGTGGTCGTTGG-3'. Indel mutations were confirmed by sequencing (Eurofins Genomics LLC, Louisville, KY, USA) of gel-purified PCR products cloned into the pJet1.2 cloning vector (Life Technologies).

Adult mosaic zebrafish (F0) were anesthetized in pH-buffered $0.2 \mathrm{mg} / \mathrm{mL}$ ethyl 3aminobenzoate methanesulfonate solution (MS-222, Sigma-Aldrich, Oakville, ON, Canada). The caudal fin ( $2 \mathrm{~mm}$ of the end) was removed using dissecting scissors (WPI Inc., Sarasota, FL, USA) and placed into $1.5 \mathrm{~mL}$ collecting tubes. The fin gDNA was isolated and screened for indel mutations as described (Bedell et al., 2012). Adult F0 zebrafish were out-crossed to wild-type (WT) TL zebrafish and their F1 offspring were analyzed by PCR and HindIII restriction digestions to verify germline transmission of mutations. Heterozygous $\mathrm{pan} \times 1 b^{+/-}$ F2 mutants were in-crossed to establish homozygous F3 mutants panx $1 b^{-/-}$. All experiments described were performed with progenies of $>\mathrm{F} 3$ generations. Later generations were routinely tested for the identity of the genotype and backcrossed into TL to preserve the line.

Gene expression and transcriptome analysis-Total RNA was extracted from $6 \mathrm{dpf}$ larvae (RNeasy Plus Mini Kit; Qiagen) and reversed transcribed (iScript Reverse Transcription Supermix; Bio-Rad Laboratories, Mississauga, ON, Canada). The cDNA equivalent of 15 ng total RNA was analyzed in triplicate by qRT-PCR (SsoAdvanced SybrGreen PCR mix; Bio-Rad). All experiments included a melt curve analysis of PCR amplicons generated in each reaction. Raw cycle threshold values (Ct-values) were exported from the CFX Manager Software (Bio-Rad, Canada), and the relative gene expression was calculated using the Relative Expression Software Tool (REST-2009) [52]. All primer sequences (Integrated DNA Technologies Inc. Coralville, Iowa) are listed in the Table 5.

The transcriptomes of the zebrafish lines used in this research were analysed by RNAseq (NGS-Facility, The Center for Applied Genomics, SickKids, Toronto, ON, Canada). The data derived from the sequencing of three independent pools of $\approx 30$ age-matched larvae (6 dpf). Details of the bioinformatical analysis have been reported [19]. A twostep differential transcript expression analysis was performed. In the first step the transcript abundance estimation using RSEM (RNA-Seq by Expectation-Maximation) version 1.3.3 (http:/ / deweylab.github.io/RSEM/, 20 September 2020) and bowtie2 version bowtie/2.3.4.2 (http:/ / bowtie-bio.sourceforge.net/index.shtml) was applied to estimate the expression level of each sample. For each sample, RSEM reports generated read counts, estimated lengths and FPKM (Fragments Per Kilobase of transcript per Million mapped reads) for each transcript and gene. In the final step estimated reads counts for each transcript from the RSEM output were complied. This transcript expression matrix was supplied to DESeq2 (https:/ / bioconductor.org/packages/release/bioc/html/DESeq2.html, 20 September 2020) v.1.22.2 to detect differentially expressed transcripts. Filtering of the low expressed transcripts to increase power was automatically applied via independent filtering on the mean of normalized counts within the DESeq results() function. The raw transcriptome data are available at the NCBI Gene Expression Omnibus (GEO) database entry GSE181853. 
Table 5. Primer sequences used for RT-qPCR.

\begin{tabular}{|c|c|c|c|c|}
\hline Gene & ID & Forward Primer $\left(5^{\prime}-3^{\prime}\right)$ & Reverse Primer $\left(5^{\prime}-3^{\prime}\right)$ & $\begin{array}{c}\text { Amplicon } \\
\text { (bp) }\end{array}$ \\
\hline per1a & NM_001030183 & GGAAAAGGCTCAGCCACAGA & TGAACTTCCGCTCAAAAGAC & 105 \\
\hline per $1 b$ & NM_212439 & GAGGGAGACAGTCAAACAGAAG & AGAAGGGCTGTGAGAGTTTG & 116 \\
\hline per2 & NM_182857 & CGTGCCCATTACAGTGAAGAG & ATGTTGACAGACCTGACTGC & 149 \\
\hline per3 & NM_131584 & CAAGTACAAGCAAACAGCGAG & ACTACCACAAAAGAGTCCGTG & 146 \\
\hline arntl1a/bmal1a & NM_131577 & TCAGATTGTTCCTGGTATTCCTG & GCGTGGCAGTGATGTTTAAAG & 149 \\
\hline arntl1b/bmal1b & NM_178300 & GAGTTCATGTCTCCCAGTTCC & GTCCTTGTCTGTGTCCATACTG & 147 \\
\hline arntl2/bmal2 & NM_131578 & ATGAACTCAAGCACCTCGTC & СТCTGTCCAATTAACTCCGTCC & 139 \\
\hline$n r 1 d 1$ & NM_205729 & AGCGACCTCCAAACAGTAAC & GGGTCTGAGTAAGGATGCATG & 142 \\
\hline clocka & NM_130957 & CATCTCTTGTGTCTCAGCCTC & GTCTCTGGATGTTTGCCTCA & 150 \\
\hline clockb & NM_178295 & GGTGGATCATGGAGAAGTGT & ATATACAGGCGGTTTCTTGGG & 148 \\
\hline clock2/npas2 & NM_178299 & AACATCCTGAACTTCCTGCC & GTTTCCCCTCGCTATATGACAG & 150 \\
\hline cipca & NM_001327903 & TTGTCCTCAAGCAGCCGAAC & GTACTGTCACCGCTGGGTAA & 136 \\
\hline cry $1 a$ & NM_001077297 & СТССАCGACAАTCСТТСАСТС & CGTCCAAGTCTTCCAAACAC & 148 \\
\hline cry $1 b$ & NM_131786 & GGTTGGACAAGCTCACAAAC & TTCCTTGGTTAGATGCCGTC & 126 \\
\hline cry2 & NM_131786 & CTGTCATGTCGCGTGTTTTAC & CAAAGTTAGGGTTATTGGTGCC & 142 \\
\hline cry $3 b$ & NM_131792 & CAGCAAATGTAAACCGTGGAG & CСTGACCCTATAAGACGATGC & 80 \\
\hline cry5 & NM_131788 & CATGACTCAGTTACGACAGGAG & TCAGCGACCAATCAGAATCC & 149 \\
\hline $18 s$ rRNA & NM_001098396 & TGCATGGCCGTTCTTAGTTG & AGTCTCGTTCGTTATCGGAATGA & 86 \\
\hline panx1a & NM_200916 & TGGATACAAACAGCTCTGTGATAG & ATCCTTTAGAGTAGCGCTTGG & 96 \\
\hline panx $1 b$ & NM_001100030 & AAGTATAAAGGCGTGCGGCTGG & TGATCTGAGTACCCACAGAGAC & 129 \\
\hline panx 2 & NM_001256641 & TCGACTGAGAGGACAAACCC & TCGCCACCAACTTCACAACTC & 99 \\
\hline panx3 & XM_001919826 & CATACAACCGCTCTGTCCGT & GCTTGCGTTTGGCTCTCTC & 105 \\
\hline
\end{tabular}

Cell culture, Panx1b transfection, and imaging-Neuroblastoma 2a (Neuro2a) cells were cultivated in DMEM with $2 \mathrm{mM}$ glutamine, $1 \%$ nonessential amino acids (NEAA), $1 \%$ penicillin, and streptomycin (PS), and $10 \%$ fetal bovine serum at $37{ }^{\circ} \mathrm{C}$ and $5 \% \mathrm{CO}_{2}$ in a humid-controlled incubator. Cells were transfected with $200 \mathrm{ng}$ total endotoxin-free plasmid DNA using the Effectene transfection protocol (Qiagen Inc., Valencia, CA, USA). Plasmid DNA encoded for C-terminally EGFP- or DsRed-monomer tagged Panx1b fusion proteins, containing the full-length protein-coding region of Panx1b (aa 1-422; Gene ID: 567417) or the truncated Panx1b aa 1-179 mutant. At 48 h post transfected cells were fixed with $4 \%$ paraformaldehyde for $20 \mathrm{~min}$ at room temperature before washing with $1 \times$ PBS and mounted for imaging with ProLong ${ }^{\circledR}$ Antifade mounting media (Thermo Fisher Inc., Mississauga, ON, Canada). The fixed samples were imaged using a Zeiss LSM 700 confocal microscope with a Plan-Apochromat $63 \times /$ NA 1.4 Oil DIC M27 objective using the ZEN 2010 program interface. Images were collected by line averaging $(4 \times)$ at $2048 \times$ 2048-pixel resolution.

Panx1b antibody production-A polyclonal anti-Panx $1 b$ antibody was generated against an affinity-purified GST-Panx1b fusion protein representing the carboxy-terminal amino acids 286-422 of Panx1b. The antibody was produced in rabbit and affinity-purified by Davids Biotechnologie GmbH (code\#ZOI-B2; Regensburg, Germany). The specificity in immunohistochemistry was validated using retina and brain tissues from adult TL and panx1b knock out fish. Control reactions without primary antibody complemented the tests. Despite extensive testing, the affinity-purified IgG antibody failed in all western blot conditions tested, like the chicken anti-Panx1b reported in an earlier study [16].

Immunohistochemistry-Adult zebrafish were humanely euthanized in MS-222 solution $(0.02 \% w / v$, Sigma-Aldrich). Tissues were removed and fixed in $4 \%$ paraformaldehyde (PFA) in 1xPBS overnight at $4{ }^{\circ} \mathrm{C}$, followed by cryoprotection in $30 \%$ sucrose in $1 \times$ PBS. After embedding in Tissue-Tek O.C.T compound $15 \mu \mathrm{m}$ sections were cut on a cryotome (Thermofisher). Samples were washed three times for 5 min with $1 \times$ PBS containing $0.1 \%$ Tween-20 (PBST) at RT. Unspecific binding sites were blocked with freshly prepared 5\% normal goat serum (NGS, Sigma-Aldrich) in PBST for $1 \mathrm{~h}$ at RT ${ }^{\circ} \mathrm{C}$. Following blocking, samples were incubated with primary antibody (1:50, affinity-purified rabbit anti-panx $1 b$ an- 
tibody, code\#ZOI-B2, Davids Biotechnologie GmbH; 1:100, rabbit anti-GFAP, code AB5804, Sigma-Aldrich) overnight at $4{ }^{\circ} \mathrm{C}$. Subsequent washes with PBST were for one hour at $4{ }^{\circ} \mathrm{C}$. The Alexa 488 goat anti-rabbit secondary antibody (1:1500 in 1\% NGS PBST, Life Technologies) was applied for one $\mathrm{hr}$ at $\mathrm{RT}{ }^{\circ} \mathrm{C}$. After 3 washed with PBST followed by one wash water, specimens were mounted on microscope slides using ProLong Antifade with DAPI (Thermofisher). Confocal images were collected using LSM-ZEN2 software (Zeiss LSM700 system; Carl Zeiss MicroImaging, Oberkochen, Germany) with Plan-Apochromat $20 \times / 0.8$ or Plan-Apochromat $63 \times / 1.3$ oil DIC M27 objectives. For comparison of wild type and knockout tissues settings for raw image collection were kept identical. Post image collection composite figures were created using Adobe Photoshop 2021.

Behavioral testing-The freely swimming behavior assay visual-motor response (VMR) was tested using larvae at $6 \mathrm{dpf}$ using a Zebrabox ${ }^{\circledR}$ behavior recording system (ViewPoint Life Technology, Lyon, France), and the Zebralab software (ViewPoint Life Technology, Lyon, France). Tracking videos were recorded at 30 frames per second (fps) under infrared light illumination using a Point Grey Research Dragonfly2 DR2-HIBW. A lightbox provided infrared (for Light-OFF recording) or visible light (for Light-ON recording). All experiments were performed at $28^{\circ} \mathrm{C}$. At least three independent experiments were performed for each assay type.

Freely swimming behavior assay-Larval swimming activity under constant LightON/OFF conditions was tested using 48-well plates. Larvae were adapted to the environment for $3 \mathrm{~h}$ before recording begins. For tracking in light, larvae were adapted to ambient light ( $30 \%$ of final output intensity). For tracking in the dark, larvae were acclimatized to darkness ( $0 \%$ of final output intensity) for $3 \mathrm{~h}$. Next, locomotor behavior was tracked for $60 \mathrm{~min}$. For analysis of locomotion, three thresholds were defined: slow $(<2 \mathrm{~mm})$, medium $(2-20 \mathrm{~mm})$, and fast $(>20 \mathrm{~mm})$. The mean traveled distance $(\mathrm{mm})$ and velocity $(\mathrm{mm} / \mathrm{s})$ in two swim speeds (medium and fast) was used for statistical analysis.

The visual-motor response (VMR) assay-Larvae in 48-well plates were adapted to darkness (Light OFF) for $3 \mathrm{~h}$. After dark adaptation, baseline locomotion was recorded. Then, three trials of alternating light onset (Light ON) and light offset (Light OFF) periods with each period lasting $30 \mathrm{~min}$, for a total of $180 \mathrm{~min}$, followed. The Light-ON stimulus was set to $100 \%$, and the Light-OFF stimulus was set at $0 \%$ of the final output intensity. In the Quantization ${ }^{\circledR}$ mode of the Zebralab software threshold settings for activity detection in successive video frames were defined as no movement $(<6)$, medium (6-20), activity burst $(>20)$. Activity data were collected per second, with periods selected for analysis outlined in results.

The optomotor response assay-OMR assays were performed using a custom-built system, which follows the design described [53]. Briefly, stimuli were presented from below using an ASUS P3B 800-Lumen LED portable projector (https: / /www.asus.com/ ca-en/Projectors/P3B/). The fish movements were recorded using a USB 3.1 high-speed camera (XIMEA GmbH, Münster, Germany) equipped with a $35 \mathrm{~mm}$ C Series Fixed Focal Length Lens (Edmund Optics Inc., Barrington, NJ, USA). An $830 \mathrm{~nm}$ long-pass filter (Edmund Optics Inc., Barrington, NJ, USA) was used to block infrared illumination coming from a source at the bottom of the test environment. The videos were recorded using the XIMEA Windows Software Package (https:/ / www.ximea.com/support/wiki/ apis/XIMEA_Windows_Software_Package). The visual stimuli were generated using the "Moving Grating" program, an online stimulus generator freely available at http: //michael-bach.de/stim/. The Visual stimulus consisted of sequences of binary (i.e., "black and white" or "gray and white") bars. The stimuli were generated with three spatial frequencies $(64,128$ and 256 pixels/cycles). Each spatial frequency was tested at two different speed rates (72 and 144 pixels/s), and two contrast levels (i.e., 10 and 100\% of the final contrast output on the program, resulting in "gray and white" or "black and white" bars, respectively). Stimuli were presented to larvae $(\mathrm{n}=10)$ for $90 \mathrm{~s}$, twice in each left or right direction. Multiple larvae (6 dpf) were transferred to a $3 \mathrm{~cm}$ Petri dish (Thermo Scientific, Waltham, MA, USA) and allowed to acclimatize for $5 \mathrm{~min}$ before video recording 
and locomotion tracking. To quantify the population response to optomotor stimuli, the Petri dish was subdivided into three zones: for each grating motion direction, the last section of the area was denoted as the "target zone". The proportion of the larvae in the "target zone" at the end of each trial was counted in relation to the total number of fish and called the percentage of positive response (PPR). The difference in the PPR of the fish after a rightward or a leftward presentation of a stimulus is a measure of the strength of the optomotor response.

Principal Component Analysis-VMR data represent seven variables: the counts and the duration of time larvae spend performing each of the three predefined swimming parameters (i.e., freeze, scoot, and burst) plus the total activity duration (TAD). In order to unambiguously evaluate the nature of behavioral responses to visual stimuli, the multiple components were disentangled by a principal component analysis (PCA) using the "FactoMineR" and "factoextra" packages. First, the PCA scores were Varimax rotated in accord with the standard PCA approach. The orthogonal configuration of varimax rotation guarantees the different components are uncorrelated, thus each represents an independent behavioral pattern. The resulting values termed "eigenvalues" signify the amount of variance explained by each of the components. To visualize and compare the size of the eigenvalues we used Scree plots. Only the first two components were retained for further interpretation, as their eigenvalues were greater than 1 and they accounted for more than $90 \%$ of total variance in the data. Next, the variables contribution percentage to each of the two retained components were computed and plotted. The most informative variable, "TAD", was compared between groups using nonparametric rank-based exact multiple contrast testing and simultaneous confidence intervals (MCTP/SCI) (nparcomp package; http://www.R-project.org). Mean TAD values of the entire test period were plotted to show control and mutant larvae activity patterns. The activity data from $1 \mathrm{~min}$ before ( $-60 \mathrm{~s})$ to $1 \mathrm{~min}$ after ( $+60 \mathrm{~s}$ ) light changes were plotted separately to visualize the locomotor activity differences of the two genotypes upon after abrupt light switches. To visualize the effects of different drugs treatments on "frect" and "TAD" of larvae upon light switches, we used line charts. The baseline activity (from $1 \mathrm{~min}$ before light switches) were used to compare the amount of change occurring in any of the two mentioned activity features during the first $1 \mathrm{~s}$ after light switches.

Statistics and data reproducibility-Unless otherwise stated, all statistical analyses were performed in R software version 3.4.0 (http:/ / www.r-project.org). A $p$-value $<0.05$ was considered statistically significant. The average values for the survival rate, body size, traveled distance, and velocity were compared between two groups using Student's $t$-test (with equal variance) or Welch's $t$-test (without equal variance) as indicated. Details of procedures and software packages used for the VMR analysis are described before [54]. For the OMR data a multiple regression model was used to assess the statistical significance of the difference between groups' PPR mean vectors. Two R packages, i.e., "tidyverse" and "car," were used for the analysis. The normality and homogeneity of the data variance were checked by the "Shapiro-Wilk Test" and "Levene's Test," respectively. The "lm" and the model statistical "summary" functions were used to fit a regression model. Then, the "TukeyHSD" function was used to detect the significant differences. The sample sizes (n) reported corresponding to the number of larvae tested. The minimum number of independent experimental replicates was $\mathrm{n} \geq 3$.

Author Contributions: Conceptualization, N.S. and G.R.Z.; formal analysis, N.S. and G.R.Z.; investigation, all authors; resources, G.R.Z.; writing—original draft preparation, N.S.; writing-review and editing, all authors; visualization, N.S. and G.R.Z.; supervision, G.R.Z.; project administration and funding acquisition, G.R.Z. All authors have read and agreed to the published version of the manuscript.

Funding: This research was supported by a Natural Sciences and Engineering Research Council (NSERC) discovery grant RGPIN—418142-2012 (GRZ). 
Data Availability Statement: RNA-sequencing are available at the NCBI Gene Expression Omnibus (GEO) database (entry GSE181853).

Acknowledgments: We thank Janet Fleites-Medina and Veronica Scavo for zebrafish husbandry.

Conflicts of Interest: The authors declare no conflict of interest.

\section{References}

1. Dahl, G. ATP release through pannexon channels. Philos. Trans. R. Soc. B Biol. Sci. 2015, 370, 20140191. [CrossRef]

2. Mim, C.; Perkins, G.; Dahl, G. Structure versus function: Are new conformations of pannexin 1 yet to be resolved? J. Gen. Physiol. 2021, 153, e202012754. [CrossRef] [PubMed]

3. Deng, Z.; He, Z.; Maksaev, G.; Bitter, R.M.; Rau, M.; Fitzpatrick, J.A.J.; Yuan, P. Cryo-EM structures of the ATP release channel pannexin 1. Nat. Struct. Mol. Biol. 2020, 27, 373-381. [CrossRef]

4. Jin, Q.; Zhang, B.; Zheng, X.; Li, N.; Xu, L.; Xie, Y.; Song, F.; Bhat, E.A.; Chen, Y.; Gao, N.; et al. Cryo-EM structures of human pannexin 1 channel. Cell Res. 2020, 30, 449-451. [CrossRef] [PubMed]

5. Michalski, K.; Syrjanen, J.L.; Henze, E.; Kumpf, J.; Furukawa, H.; Kawate, T. The Cryo-EM structure of pannexin 1 reveals unique motifs for ion selection and inhibition. eLife 2020, 9, e54670. [CrossRef] [PubMed]

6. Mou, L.; Ke, M.; Song, M.; Shan, Y.; Xiao, Q.; Liu, Q.; Li, J.; Sun, K.; Pu, L.; Guo, L.; et al. Structural basis for gating mechanism of Pannexin 1 channel. Cell Res. 2020, 30, 452-454. [CrossRef]

7. Qu, R.; Dong, L.; Zhang, J.; Yu, X.; Wang, L.; Zhu, S. Cryo-EM structure of human heptameric Pannexin 1 channel. Cell Res. 2020, 30, 446-448. [CrossRef] [PubMed]

8. Ruan, Z.; Orozco, I.J.; Du, J.; Lü, W. Structures of human pannexin 1 reveal ion pathways and mechanism of gating. Nature 2020, 584, 646-651. [CrossRef]

9. Ray, A.; Zoidl, G.; Weickert, S.; Wahle, P.; Dermietzel, R. Site-Specific and developmental expression of pannexin1 in the mouse nervous system. Eur. J. Neurosci. 2005, 21, 3277-3290. [CrossRef]

10. Dvoriantchikova, G.; Ivanov, D.; Barakat, D.; Grinberg, A.; Wen, R.; Slepak, V.Z.; Shestopalov, V.I. Genetic Ablation of Pannexin1 Protects Retinal Neurons from Ischemic Injury. PLoS ONE 2012, 7, e31991. [CrossRef]

11. Dvoriantchikova, G.; Ivanov, D.; Panchin, Y.; Shestopalov, V.I. Expression of pannexin family of proteins in the retina. FEBS Lett. 2006, 580, 2178-2182. [CrossRef] [PubMed]

12. Kranz, K.; Dorgau, B.; Pottek, M.; Herrling, R.; Schultz, K.; Bolte, P.; Monyer, H.; Penuela, S.; Laird, D.W.; Dedek, K.; et al. Expression of Pannexin1 in the outer plexiform layer of the mouse retina and physiological impact of its knockout. J. Comp. Neurol. 2012, 521, 1119-1135. [CrossRef] [PubMed]

13. Pronin, A.; Pham, D.; An, W.; Dvoriantchikova, G.; Reshetnikova, G.; Qiao, J.; Kozhekbaeva, Z.; Reiser, A.E.; Slepak, V.Z.; Shestopalov, V.I. Inflammasome Activation Induces Pyroptosis in the Retina Exposed to Ocular Hypertension Injury. Front. Mol. Neurosci. 2019, 12, 36. [CrossRef] [PubMed]

14. Ravi, V.; Venkatesh, B. The Divergent Genomes of Teleosts. Annu. Rev. Anim. Biosci. 2018, 6, 47-68. [CrossRef]

15. Bond, S.R.; Wang, N.; Leybaert, L.; Naus, C.C. Pannexin 1 Ohnologs in the Teleost Lineage. J. Membr. Biol. 2012, 245, 483-493. [CrossRef]

16. Kurtenbach, S.; Prochnow, N.; Kurtenbach, S.; Klooster, J.; Zoidl, C.; Dermietzel, R.; Kamermans, M.; Zoidl, G. Pannexin1 Channel Proteins in the Zebrafish Retina Have Shared and Unique Properties. PLoS ONE 2013, 8, e77722. [CrossRef]

17. Prochnow, N.; Hoffmann, S.; Vroman, R.; Klooster, J.; Bunse, S.; Kamermans, M.; Dermietzel, R.; Zoidl, G. Pannexin1 in the outer retina of the zebrafish, Danio rerio. Neuroscience 2009, 162, 1039-1054. [CrossRef]

18. Cenedese, V.; de Graaff, W.; Csikós, T.; Poovayya, M.; Zoidl, G.; Kamermans, M. Pannexin 1 Is Critically Involved in Feedback from Horizontal Cells to Cones. Front. Mol. Neurosci. 2017, 10, 403. [CrossRef]

19. Safarian, N.; Whyte-Fagundes, P.; Zoidl, C.; Grigull, J.; Zoidl, G. Visuomotor deficiency in panx1a knockout zebrafish is linked to dopaminergic signaling. Sci. Rep. 2020, 10, 1-14. [CrossRef]

20. Bedell, V.; Wang, Y.; Campbell, J.M.; Poshusta, T.L.; Starker, C.; Ii, R.G.K.; Tan, W.; Penheiter, S.G.; Ma, A.C.; Leung, A.Y.H.; et al. In Vivo genome editing using a high-efficiency TALEN system. Nature 2012, 491, 114-118. [CrossRef]

21. Prochnow, N.; Hoffmann, S.; Dermietzel, R.; Zoidl, G. Replacement of a single cysteine in the fourth transmembrane region of zebrafish pannexin1 alters hemichannel gating behavior. Exp. Brain Res. 2009, 199, 255-264. [CrossRef]

22. Hirayama, J.; Kaneko, M.; Cardone, L.; Cahill, G.; Sassone-Corsi, P. Analysis of Circadian Rhythms in Zebrafish. Methods Enzymol. 2005, 393, 186-204. [CrossRef]

23. Emran, F.; Rihel, J.; Dowling, J.E. A Behavioral Assay to Measure Responsiveness of Zebrafish to Changes in Light Intensities. J. Vis. Exp. 2008, e923. [CrossRef]

24. Bilotta, J. Effects of abnormal lighting on the development of zebrafish visual behavior. Behav. Brain Res. 2000, 116, 81-87. [CrossRef]

25. Neuhauss, S.C. Behavioral genetic approaches to visual system development and function in zebrafish. J. Neurobiol. 2002, 54, 148-160. [CrossRef]

26. Portugues, R.; Engert, F. The neural basis of visual behaviors in the larval zebrafish. Curr. Opin. Neurobiol. 2009, 19, 644-647. [CrossRef] [PubMed] 
27. Stiebel-Kalish, H.; Reich, E.; Rainy, N.; Vatine, G.; Nisgav, Y.; Tovar, A.; Gothilf, Y.; Bach, M. Gucy2f zebrafish knockdown-A model for Gucy2d-related leber congenital amaurosis. Eur. J. Hum. Genet. 2012, 20, 884-889. [CrossRef]

28. Prochnow, N.; Abdulazim, A.; Kurtenbach, S.; Wildförster, V.; Dvoriantchikova, G.; Hanske, J.; Petrasch-Parwez, E.; Shestopalov, V.I.; Dermietzel, R.; Manahan-Vaughan, D.; et al. Pannexin1 Stabilizes Synaptic Plasticity and Is Needed for Learning. PLoS ONE 2012, 7, e51767. [CrossRef]

29. Dvoriantchikova, G.; Pronin, A.; Kurtenbach, S.; Toychiev, A.; Chou, T.-H.; Yee, C.W.; Prindeville, B.; Tayou, J.; Porciatti, V.; Sagdullaev, B.; et al. Pannexin 1 sustains the electrophysiological responsiveness of retinal ganglion cells. Sci. Rep. 2018, 8, 5797. [CrossRef] [PubMed]

30. Kist, A.; Portugues, R. Optomotor Swimming in Larval Zebrafish Is Driven by Global Whole-Field Visual Motion and Local Light-Dark Transitions. Cell Rep. 2019, 29, 659-670. [CrossRef] [PubMed]

31. Kramer, A.; Wu, Y.; Baier, H.; Kubo, F. Neuronal Architecture of a Visual Center that Processes Optic Flow. Neuron 2019, 103, 118-132. [CrossRef]

32. Naumann, E.A.; Fitzgerald, J.E.; Dunn, T.W.; Rihel, J.; Sompolinsky, H.; Engert, F. From Whole-Brain Data to Functional Circuit Models: The Zebrafish Optomotor Response. Cell 2016, 167, 947-960. [CrossRef]

33. Portugues, R.; Engert, F. Adaptive Locomotor Behavior in Larval Zebrafish. Front. Syst. Neurosci. 2011, 5, 72. [CrossRef] [PubMed]

34. Orger, M.; Baier, H. Channeling of red and green cone inputs to the zebrafish optomotor response. Vis. Neurosci. 2005, 22, 275-281. [CrossRef]

35. Zhou, M.; Bear, J.; Roberts, P.A.; Janiak, F.K.; Semmelhack, J.; Yoshimatsu, T.; Baden, T. Zebrafish Retinal Ganglion Cells Asymmetrically Encode Spectral and Temporal Information across Visual Space. Curr. Biol. 2020, 30, 2927-2942. [CrossRef] [PubMed]

36. Abbas, F.; Triplett, M.A.; Goodhill, G.; Meyer, M.P. A Three-Layer Network Model of Direction Selective Circuits in the Optic Tectum. Front. Neural Circuits 2017, 11, 88. [CrossRef] [PubMed]

37. Tikidji-Hamburyan, A.; Reinhard, K.; Seitter, H.; Hovhannisyan, A.; Procyk, C.; Allen, A.E.; Schenk, M.; Lucas, R.; Münch, T.A. Retinal output changes qualitatively with every change in ambient illuminance. Nat. Neurosci. 2014, 18, 66-74. [CrossRef]

38. Trenholm, S.; McLaughlin, A.J.; Schwab, D.J.; Awatramani, G.B. Dynamic Tuning of Electrical and Chemical Synaptic Transmission in a Network of Motion Coding Retinal Neurons. J. Neurosci. 2013, 33, 14927-14938. [CrossRef]

39. Trenholm, S.; McLaughlin, A.J.; Schwab, D.J.; Turner, M.H.; Smith, R.G.; Rieke, F.; Awatramani, G.B. Nonlinear dendritic integration of electrical and chemical synaptic inputs drives fine-scale correlations. Nat. Neurosci. 2014, 17, 1759-1766. [CrossRef] [PubMed]

40. Vaney, D.I. Territorial organization of direction-selective ganglion cells in rabbit retina. J. Neurosci. 1994, 14, 6301-6316. [CrossRef] [PubMed]

41. Yao, X.; Cafaro, J.; McLaughlin, A.J.; Postma, F.R.; Paul, D.L.; Awatramani, G.; Field, G.D. Gap Junctions Contribute to Differential Light Adaptation across Direction-Selective Retinal Ganglion Cells. Neuron 2018, 100, 216-228. [CrossRef] [PubMed]

42. Mu, Y.; Bennett, D.; Rubinov, M.; Narayan, S.; Yang, C.-T.; Tanimoto, M.; Mensh, B.D.; Looger, L.L.; Ahrens, M.B. Glia Accumulate Evidence that Actions Are Futile and Suppress Unsuccessful Behavior. Cell 2019, 178, 27-43. [CrossRef]

43. Halassa, M.M.; Fellin, T.; Haydon, P.G. Tripartite synapses: Roles for astrocytic purines in the control of synaptic physiology and behavior. Neuropharmacology 2009, 57, 343-346. [CrossRef] [PubMed]

44. Bazargani, N.; Attwell, D. Astrocyte calcium signaling: The third wave. Nat. Neurosci. 2016, 19, 182-189. [CrossRef]

45. Suadicani, S.O.; Iglesias, R.; Wang, J.; Dahl, G.; Spray, D.C.; Scemes, E. ATP signaling is deficient in cultured pannexin1-null mouse astrocytes. Glia 2012, 60, 1106-1116. [CrossRef] [PubMed]

46. Beckel, J.M.; Argall, A.J.; Lim, J.C.; Xia, J.; Lu, W.; Coffey, E.E.; Macarak, E.J.; Shahidullah, M.; Delamere, N.; Zode, G.S.; et al. Mechanosensitive release of adenosine $5^{\prime}$-triphosphate through pannexin channels and mechanosensitive upregulation of pannexin channels in optic nerve head astrocytes: A mechanism for purinergic involvement in chronic strain. Glia 2014, 62, 1486-1501. [CrossRef]

47. Marpegan, L.; Swanstrom, A.E.; Chung, K.; Simon, T.; Haydon, P.G.; Khan, S.K.; Liu, A.C.; Herzog, E.; Beaulé, C. Circadian Regulation of ATP Release in Astrocytes. J. Neurosci. 2011, 31, 8342-8350. [CrossRef]

48. Kovalzon, V.; Moiseenko, L.; Ambaryan, A.; Kurtenbach, S.; Shestopalov, V.; Panchin, Y. Sleep-Wakefulness cycle and behavior in pannexin1 knockout mice. Behav. Brain Res. 2017, 318, 24-27. [CrossRef]

49. Shestopalov, V.I.; Panchin, Y.; Tarasova, O.S.; Gaynullina, D.; Kovalzon, V.M. Pannexins Are Potential New Players in the Regulation of Cerebral Homeostasis during Sleep-Wake Cycle. Front. Cell. Neurosci. 2017, 11. [CrossRef]

50. Neff, K.L.; Argue, D.P.; Ma, A.C.; Lee, H.B.; Clark, K.J.; Ekker, S.C. Mojo Hand, a TALEN design tool for genome editing applications. BMC Bioinform. 2013, 14, 1-7. [CrossRef]

51. Cermak, T.; Doyle, E.L.; Christian, M.; Wang, L.; Zhang, Y.; Schmidt, C.; Baller, J.A.; Somia, N.V.; Bogdanove, A.J.; Voytas, D.F. Efficient design and assembly of custom TALEN and other TAL effector-based constructs for DNA targeting. Nucleic Acids Res. 2011, 39, e82. [CrossRef] [PubMed]

52. Bedell, V.; Ekker, S.C. Using Engineered Endonucleases to Create Knockout and Knockin Zebrafish Models. In Chromosomal Mutagenesis; Humana Press: New York, NY, USA, 2015; pp. 291-305. [CrossRef] 
53. Pfaffl, M.W.; Horgan, G.W.; Dempfle, L. Relative expression software tool (REST(C)) for group-wise comparison and statistical analysis of relative expression results in real-time PCR. Nucleic Acids Res. 2002, 30, e36. [CrossRef] [PubMed]

54. Štih, V.; Petrucco, L.; Kist, A.M.; Portugues, R. Stytra: An open-source, integrated system for stimulation, tracking and closed-loop behavioral experiments. PLoS Comput. Biol. 2019, 15, e1006699. [CrossRef] [PubMed] 